\title{
Pelatihan Pengembangan Produk Menggunakan Prinsip Utama Heizer-Render Bagi Tenant Program Pengembangan Kewirusahaan FTI UAD
}

\author{
Amalya Nurul Khairi*, Farid Ma'ruf'2, Jefree Farhana ${ }^{3}$, Syifa Fitriani4 \\ ${ }^{1 .}$ Universitas Ahmad Dahlan, Kampus 4 Jl. Ringroad Selatan Kragilan Tamanan Banguntapan Bantul \\ 2. Universitas Ahmad Dahlan, Kampus 4 Jl. Ringroad Selatan Kragilan Tamanan Banguntapan Bantul \\ 3. Universitas Ahmad Dahlan, Kampus 4 Jl. Ringroad Selatan Kragilan Tamanan Banguntapan Bantul \\ 4. Universitas Ahmad Dahlan, Kampus 4 Jl. Ringroad Selatan Kragilan Tamanan Banguntapan Bantul \\ Email: amalya.khairi@tp.vad.ac.id \\ DOI: $10.18196 / p p m .31 .136$
}

\begin{abstract}
Abstrak
PPK FTI UAD adalah program yang bertujuan untuk membina calon-calon wirausaha dari kalangan mahasiswa dan alumni FTI. Kegiatan ini membina 20 tenant setiap tahunnya dan mengevaluasi capaian tenant untuk diberikan pendampingan dan bantuan berwirausaha. Tenant yang menjadi peserta PPK FTI terbagi menjadi mahasiswa/alumni yang telah menjalankan bisnis dan yang baru mulai merintis konsep bisnis. Wirausahawan yang dihasilkan oleh PPK FTI diharapkan memiliki pemahaman yang baik dalam bidang pengelolaan bisnis, komunikasi, penguasaan teknologi, berlandaskan nilai-nilai Islam, dan berprinsip sosiopreneur. Untuk menunjang tujuan tersebut pelatihan strategi desain produk sangat diperlukan. Pelatihan ini dilaksanakan dengan metode diskusi dan sharing secara daring menggunakan sarana aplikasi Zoom Meeting. Pelatihan ini diikuti oleh tujuh belas (17) peserta dan empat (4) pengelola PPK dengan narasumber Amalya Nurul Khairi, M.Sc. Sub topik yang dibahas dalam pelatihan ini adalah kriteria desain produk yang baik dan tiga keunggulan bersaing suatu produk disertai studi kasus. Peserta melakukan diskusi melalui sesi tanya jawab dan membagi pengalaman selama merintis bisnis, khususnya bagi tenant yang telah memiliki bisnis. Umpan balik dari peserta cukup baik yang ditandai dengan penilaian pada kuisioner mayoritas memberikan skor 4 (baik) dan 5 (sangat baik). Evaluasi yang masih perlu ditingkatkan adalah dalam hal kualitas suara (penilaian skor 3 (cukup) sejumlah 28,6\%) dan kesesuaian materi dengan harapan peserta (penilaian skor 3 (cukup) sejumlah 7,1\%).
\end{abstract}

Kata Kunci: pelatihan, strategi, desain produk, PPK

\section{Pendahuluan}

Pembinaan semangat berwirausaha dipandang perlu untuk memprioritaskan kaum muda sebagai tunas bangsa yang masih memiliki semangat tinggi, mudah diarahkan, dinamis, pantang menyerah, visioner, dan futuristik. Kaum muda yang potensial tersebut salah satunya adalah mahasiswa dan lulusan perrguruan tinggi. Program Pembinaan Kewirausahaan (PPK) adalah sebuah program pembinaan intensif dan berkelanjutan yang bertujuan untuk menumbuhkan dan mencetak wirausaha baru yang berasal dari kalangan mahasiswa dan alumni Fakultas Teknologi Industri (FTI) Universitas Ahmad Dahlan (UAD).

Walaupun dianggap potensial, kaum muda tetap memiliki kelemahan khususnya dalam hal pengalaman dan pengetahuan untuk menghadapi pasar yang semakin kompetitif dan berat. Minimnya pengalaman dan pengetahuan tersebut menyebabkan sebagian mahasiswa atau lulusan perguruan tinggi tidak berani mengambil keputusan berwirausaha dan kurang mampu mendesain produk maupun bisnis yang akan dibangunnya. Desain produk berpengaruh signifikan bagi keputusan pembelian (Dwiningwarni, et al, 2018). Menurut David (2013) desain produk adalah pengembangan dan pengaturan produk dalam rangka memperbaiki atau meningkatkan penjualan. Pengertian tersebut dapat dikembangkan menjadi suatu metode untuk mengartikan keinginan pasar yang diperoleh melalui riset dan pengembangan sehingga hasil akhirnya adalah produk yang mendatangkan laba bagi perusahaan (Dwiningwarni, et al, 2018).

Dari perspektif konsumen, desain produk yang inovatif dan mampu menjadi jalan keluar permasalahan konsumen sangat berpengaruh terhadap keputusan membeli (Hidayah, 2017). Pandemi covid-19 menyebabkan konsumen semakin selektif dalam membelanjakan uangnya dan 
memilih barang yang dikonsumsi. Kondisi tersebut menyebabkan penurunan omzet Usaha Mikro, Kecil, dan Menengah (UMKM). Oleh karena itu wirausahawan harus memikirkan semaksimal mungkin desain produk yang dapat menarik minat pembelian sehingga kerugian yang diakibatkan oleh pandemi dapat ditekan.

PPK FTI melakukan pelatihan strategi desain produk dengan tujuan untuk membekali para calon tenant yang akan diberi pendampingan intensif dan bantuan usaha agar memahami konsep produk yang memenuhi kebutuhan konsumen dan laku untuk dijual. Pelatihan ini dikembangkan dengan metode diskusi dan tanya jawab agar memudahkan pelaksana program untuk menggali dan memberi masukan bagi para calon tenant. Setelah pelatihan dilakukan, diharapkan seluruh calon tenant memiliki pemahaman dan konsep yang lebih baik terhadap produk yang akan dipasarkan.

\section{Metode Pelaksanaan}

Kegiatan ini dilakukan secara daring dengan aplikasi zoom. Peserta pelatihan merupakan calon tenant yang diseleksi dengan wawancara. Jumlah tenant yang terpilih adalah 20 tenant dari 27 tenant terdaftar. Tenant adalah mahasiswa dan alumni yang telah atau akan merintis usaha. Metode yang digunakan dalam pelatihan ini adalah metode ceramah dan Forum Group Discussion (FGD) dengan fasilitator dari Tim PPK FTI UAD yang berjumlah dua orang.

\section{Metode Ceramah}

Ceramah dilakukan dengan pemaparan materi terlebih dahulu dari pembicara/fasilitator Amalya Nurul Khairi, S.T.P., M.Sc mengenai strategi desain produk usaha. Materi diberikan dengan studi kasus dan pemaparan mengenai tiga kunci utama pengembangan produk. Ketiga kunci pengembangan produk itu antara lain kelebihan pada aspek harga, kualitas, dan kecepatan pengiriman/pelayanan.

\section{Metode Forum Group Discussion (FGD)}

Metode ini dilakukan setelah pemaparan materi dengan proses tanya jawab dan sharing pengalaman. Tenant yang telah atau akan memiliki usaha sebelumnya memberikan gambaran proses yang pernah atau sedang dilalui dan mengajukan beberapa pertanyaan. Pertanyaan tersebut dijawab oleh fasilitator dan didiskusikan bersama dengan anggota forum/tenant lain.

\section{Pendampingan desain produk}

Metode pendampingan desain produk ini dilakukan setelah forum pelatihan selesai diselenggarakan. Tenant diperkenankan berdiskusi personal dengan fasilitator jika mengalami kesulitan dan kendala selama mengembangkan bisnisnya.

\section{Hasil dan Pembahasan}

Kegiatan berkelanjutan yang dikelola oleh tim PPK FTI UAD ini bertujuan untuk menjaring tenant potensial untuk diinkubasi dan didampingi pelaksanaan bisnisnya hingga dapat secara mandiri menjadi wirausahawan baru. Rekruitmen terhadap calon tenant yang akan diinkubasi dilakukan melalui proses sosialisai dan seleksi yang disosialisasikan melalui pamflet, sosial media, maupun melalui website FTI UAD dan website alumi. Seleksi tenant dilakukan dalam dua tahap, meliputi seleksi calon 20 tenant (untuk mendapat pelatihan dan inkubasi), dan seleksi 6 tenant untuk mendapatkan bantuan usaha dan pendampingan bisnis.

Rekrutmen dilakukan pada awal bulan Maret 2020 (berakhir pada 30 Maret 2020) dan berhasil menjaring 27 pendaftar. Pendaftar tersebut terdiri dari 11 tim alumni dan 16 tim mahasiswa aktif FTI UAD. Seleksi dilakukan dengan metode wawancara secara daring pada bulan Juni dan memutuskan 20 tim lolos seleksi untuk mengikuti kegiatan inkubasi bisnis yang 
dimulai pada 27 Juni sampai 18 Juli 2020. Kedua puluh tim tersebut terdiri dari sebelas (11) tim mahasiswa dan sembilan (9) tim alumni. Usaha yang dimiliki tenant terdiri dari kuliner/makanan, desain produk, fashion, jasa, elektronik, pendidikan, multimedia, dan suplemen kesehatan. Ditargetkan setiap tahun PPK FTI akan membina 20 tenant untuk mendapatkan pelatihan inkubasi bisnis. Di akhir program akan dipilih 6 (enam) tenant pada tahun ke-1, 6 (enam) tenant pada tahun ke-2, dan 7 (tujuh) tenant pada tahun ke-3 yang dinilai siap berkiprah di masyarakat dengan pemberian bantuan usaha dan pendampingan praktik usaha.

Pelatihan strategi desain produk merupakan bagian dari kegiatan inkubasi bisnis yang bertujuan untuk memberikan gambaran kepada para tenant kriteria desain produk yang baik dan berpeluang menghasilkan laba bagi usahanya. Desain produk harus mempertimbangkan setidaknya tiga prinsip utama (Heizer and Render, 2006):

1. Diferensiasi Produk

Sebuah produk harus memiliki kekhasan yang tidak dimiliki oleh produk lain yang sejenis. Keunikan tersebut menjadikannya berbeda dan akan mendapat tempat tersendiri di hati konsumen. Keunikan dapat berupa fungsionalitas, kemudahan, desain produk yang tujuan utamanya adalah menjadi solusi bagi permasalahan yang dihadapi oleh konsumen. Keunikan tersebut akan meningkatkan kepercayaan konsumen terhadap produk yang akan dibelinya sehingga akan sangat mempengaruhi keputusan pembelian konsumen.

2. Cost leadership

Konsumen selalu menginginkan produk terbaik dengan harga terbaik untuk didapatkan. Diferensiasi produk berupa harga yang bersaing dengan produk yang sama atau sejenis akan menjadikan suatu brand terus dicari oleh konsumen. Fluktuasi penjualan dapat disebabkan oleh pesaing dan konsumen (Saraswati, et al, 2015). Pemilihan strategi ini dapat ditempuh oleh wirausaha untuk meminimalisir biaya research and development dalam pengembangan produk dan tetap memikat hati konsumen untuk memilih produk yang mereka hasilkan.

3. Fast response

Kecepatan merespon segala keluhan dan keinginan konsumen adalah sebuah pelayanan yang dapat meningkatkan loyalitas konsumen terhadap suatu produk. Loyalitas konsumen terhadap suatu produk harus dibangun dengan pelayanan yang baik dan ketanggapan produsen terhadap konsumennya. Pemilihan strategi ini banyak dilakukan oleh perusahaan atau retail cepat saji dengan segmentasi konsumen yang memiliki waktu terbatas.

Pelatihan strategi desain produk ini diikuti oleh perwakilan dari dua puluh tenant yang dapat dilihat dalam Tabel 1 dan Gambar 1.

Tabel 1. Peserta Pelatihan (Tenant PPK FTI UAD 2020)

\begin{tabular}{clll}
\hline No & \multicolumn{1}{c}{ Nama Usaha } & \multicolumn{1}{c}{ Jenis Usaha } & \multicolumn{1}{c}{ Status } \\
\hline 1 & Mutia Syar'i & Fashion & Alumni \\
2 & Si-Doel Ahmad Dahlan & Desain Produk & Mahasiswa \\
3 & Zat_case & Custom case HP & Mahasiswa \\
4 & Jasa PCB & Desain Produk & Mahasiswa \\
5 & Eltedirahijab & Fashion & Alumni \\
6 & FDJ Engineering & Desain Produk & Mahasiswa \\
7 & Bening Qalbu & Training/jasa & Alumni \\
8 & Ashiappp art & Desain Produk & Mahasiswa \\
9 & Okeanos Herbal Laut & Suplemen/kesehatan & Mahasiswa \\
10 & Dermayu Catering Jogja & Kuliner & Alumni \\
11 & Ngumbah Tapak & Jasa/fashion & Mahasiswa \\
12 & Konveksi dan Percetakan & Desain Produk & Alumni \\
\hline
\end{tabular}




\begin{tabular}{|c|c|c|c|}
\hline No & Nama Usaha & Jenis Usaha & Status \\
\hline 13 & Bengkel Las & Desain Produk & Alumni \\
\hline 14 & Zpediaku & Aplikasi & Mahasiswa \\
\hline 15 & Muvon Multimedia & Multimedia & Mahasiswa \\
\hline 16 & Martabak Manis & Kuliner & Mahasiswa \\
\hline 17 & Chicken Lemon & Kuliner & Alumni \\
\hline 18 & Mesin Tetas Telur & Desain Produk & Alumni \\
\hline 19 & Printing Kaos & Desain Produk & Alumni \\
\hline 20 & Clythoria Yoghurt & Kuliner & Mahasiswa \\
\hline
\end{tabular}

Pelatihan dilakukan dengan metode ceramah dan FGD serta pendampingan dan evaluasi BMC. Peserta dapat mengikuti pelatihan dengan baik dan lengkap dari awal sesi hingga akhir sesi. Tidak terdapat kendala teknis yang berarti selama pelatihan berlangsung.

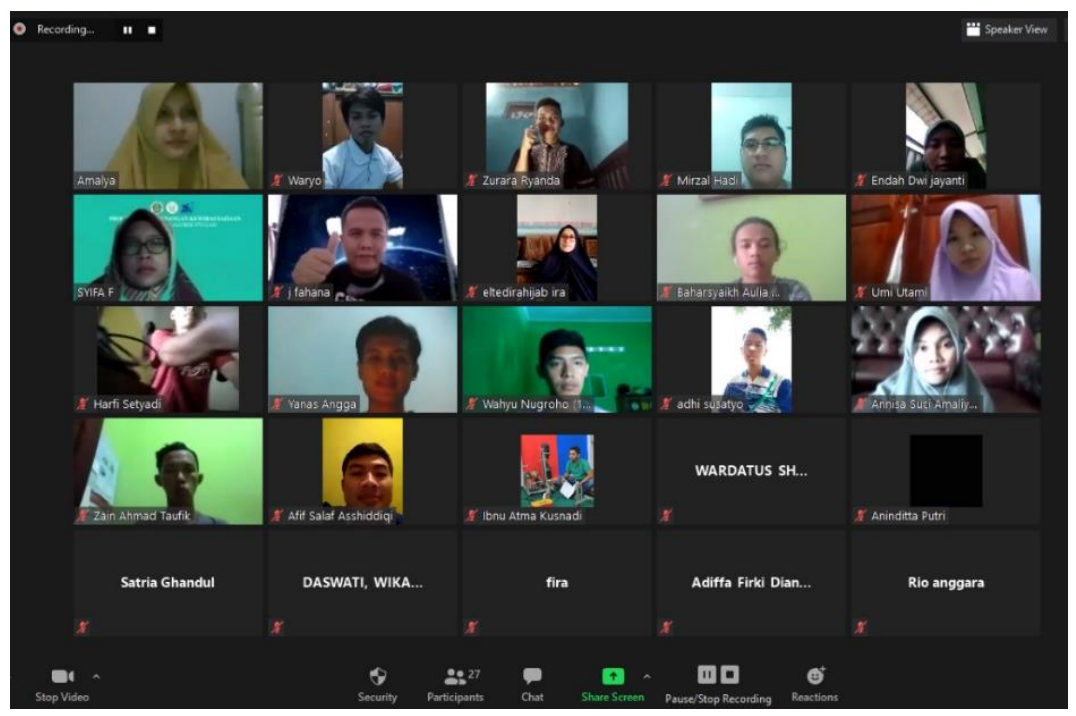

Gambar 1. Pelaksanaan Pelatihan Desain Produk PPK FTI UAD

Umpan balik dari tenant terhadap berjalannya pelatihan dijaring melalui kuisioner evaluasi yang hasilnya dapat dilihat pada Tabel 2 berikut.

Tabel 2. Umpan Balik Peserta terhadap Pelatihan

\begin{tabular}{lllllll}
\hline \multirow{2}{*}{ No } & \multicolumn{1}{c}{ Kriteria Evaluasi } & \multicolumn{5}{c}{ Persentase penilaian* peserta (\%) } \\
\cline { 3 - 7 } & & $\mathbf{1}$ & $\mathbf{2}$ & $\mathbf{3}$ & $\mathbf{4}$ & $\mathbf{5}$ \\
\hline 1 & Penyampaian materi oleh narasumber mudah dipahami & 0 & 0 & 0 & 50 & 50 \\
2 & Materi pelatihan dapat dipahami & 0 & 0 & 0 & 42,9 & 57,1 \\
3 & Kesesuaian materi narasumber dengan harapan peserta & 0 & 0 & 7,1 & 50 & 42,9 \\
4 & $\begin{array}{l}\text { Sesi tanya jawab berjalan efektif dan dapat menjawab } \\
\text { pertanyaan peserta }\end{array}$ & 0 & 0 & 0 & 42,9 & 57,1 \\
5 & Kualitas visual (teks,gambar) jelas dan jernih & 0 & 0 & 0 & 42,9 & 57,1 \\
6 & Kualitas audio (suara) sangat jelas dan jernih & 0 & 0 & 28,6 & 35,7 & 35,7 \\
\hline
\end{tabular}

*Keterangan: 1: sangat tidak baik; 2: tidak baik; 3: cukup; 4:baik; 5: sangat baik

Dari tabel tersebut dapat terlihat bahwa peserta cukup puas dengan berjalannya pelatihan yang ditandai dengan persentase nilai terbanyak ada pada nilai 4 dan 5. Evaluasi yang diberikan oleh peserta dengan nilai terendah 3 terdapat dalam kriteria kualitas suara $(28,6 \%)$ dan kesesuaian materi dengan harapan peserta $(7,1 \%)$. Evaluasi ini muncul dikarenakan pelaksanaan 
pelatihan yang menggunakan metode daring sehingga seringkali muncul kendala teknis seperti sinyal, terputusnya suara, mati listrik, dan lain sebagainya. Evaluasi kesesuaian materi narasumber dengan harapan peserta memiliki $7,1 \%$ penilaian cukup terjadi dikarenakan durasi pelatihan yang sangat singkat hanya satu pertemuan selama kurang lebih 120 menit. Padatnya materi dan terbatasnya waktu, masih diperlukan pelatihan lanjutan khususnya bagi para tenant yang baru akan memulai bisnisnya dan belum memiliki produk. Sebagai gambaran lebih jelas komposisi umpan balik tenant pelatihan dapat dilihat pada Gambar 2.
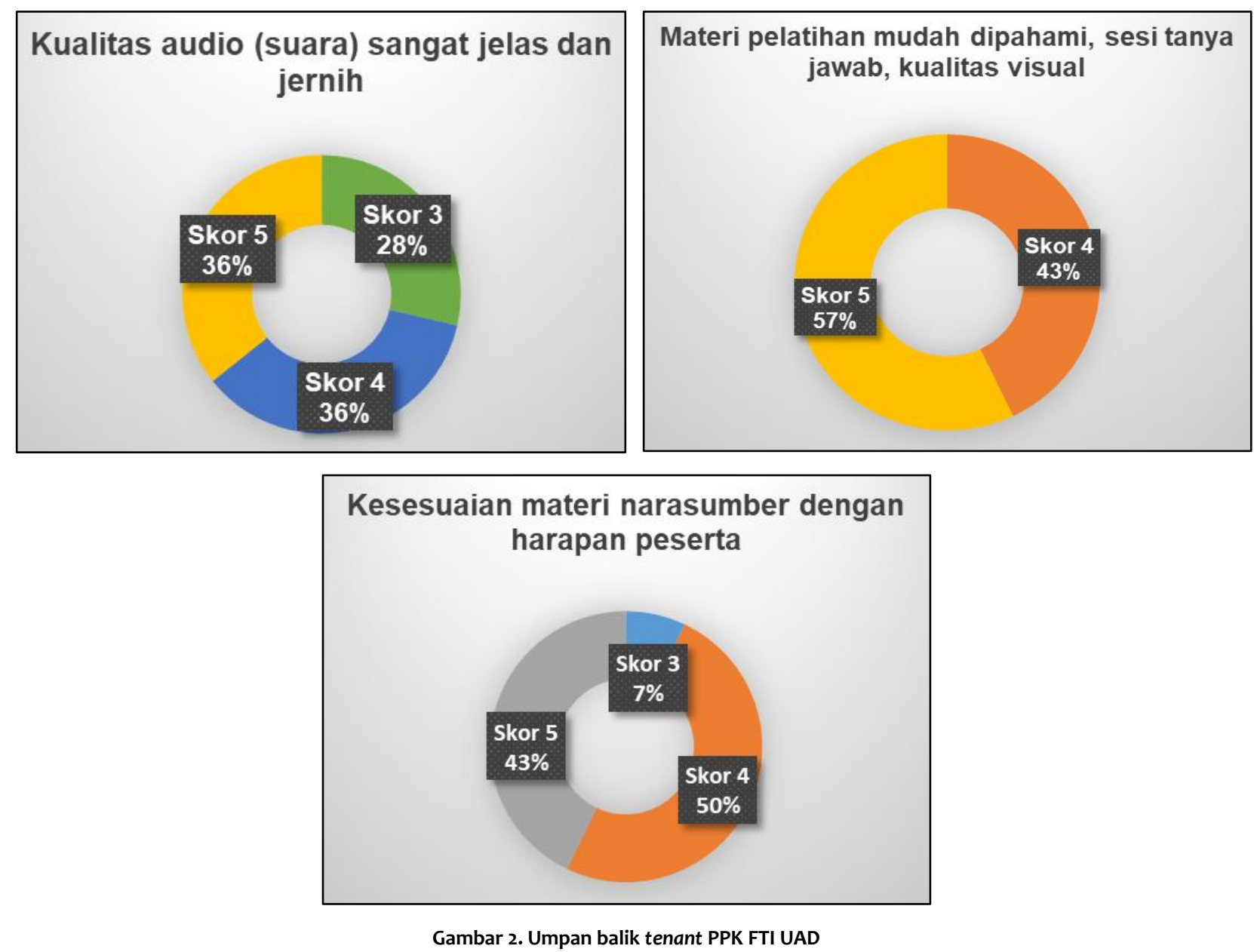

Tenant melakukan diskusi secara terpisah setelah pelatihan berlangsung dengan fasilitator dan membuat rancangan bisnisnya dalam bentuk Business Model Canvass (BMC) yang akan dievaluasi pada saat seleksi tenant untuk mendapat hibah PPK FTI UAD. Evaluasi BMC tersebut nantinya akan menyeleksi kembali 20 tenant pada pelatihan ini menjadi 6 tenant. Dengan demikian dapat disimpulkan bahwa pelatihan ini sangat diperlukan untuk awalan inkubasi tenant PPK FTI agar program PPK FTI benar-benar dapat mencetak wirausahawan baru yang mumpuni pada akhir tahun 2020.

\section{Simpulan}

1. Pelatihan desain produk diselenggarakan untuk memberi pemahaman tentang tiga kriteria utama desain produk pada tenant PPK FTI UAD

2. Respon tenant peserta PPK FTI UAD sangat baik ditandai dengan rendahnya persentase ketidakpuasan dari umpan balik pelatihan 
3. Pelatihan desain produk diperlukan sebagai awalan untuk seleksi tenant yang mendapat hibah dan sebagai awalan proses pendampingan inkubasi tenant

\section{Ucapan Terima Kasih}

Kami sampaikan terima kasih kepada RistekBRIN sebagai pemberi dana kegiatan pengabdian multi-tahun skema Program Pengembangan Kewiraushaaan Fakultas Teknologi Industri Universitas Ahmad Dahlan (PPK FTI UAD). Kami juga menghaturkan terima kasih kepada Lembaga Penelitian dan Pengabdian Masyarakat Universitas Ahmad Dahlan (LPPM UAD), Dekan, Ketua Program Studi, dan pengampu Mata Kuliah Kewirausahaan FTI UAD yang telah memberikan dukungan, arahan, fasilitas, dan bantuan untuk terselenggaranya program ini dengan baik.

\section{Daftar Pustaka}

David, F.R. 2013. Strategic Management: Concepts and Cases. Harlow, UK:Pearson.

Dwiningwarni, N.M., Anjarsari, Suhada. 2018. Pengaruh Desain Produk dan Strategi Pemasaran Terhadap Keputusan Pembelian Produk. Jurnal eBA Vol. 4 No. 1 Februari 2018. Hal. 4856

Heizer, Jay and Render, Barry. 2006. Operation Management. New Jersey:Pearson Education.

Hidayah, M.R. 2017. Pengaruh Desain Produk dan Promosi terhadap Keputusan Pembelian pada Motor Sport Yamaha 150cc di Kabupaten Klaten. Skripsi. Fakultas Ekonomi. Universitas Negeri Yogyakarta

Saraswati, M., Pradhanawati, A., Hidayat, W. 2015. Pengaruh Desain Produk, Kualitas Produk, dan Harga terhadap Keputusan Pembelian pada Kampung Batik Wiradesa, Kabupaten Pekalongan. Jurnal Ilmu Administrasi Bisnis, vol. 4, no. 2, hal. 137-146. 